\title{
The Development of Plant Maintenance Scheduling Via Inventory System for Sustainable Plant Operation
}

\author{
Roslizan Masripan ${ }^{1}$, A. M. Leman ${ }^{1,}{ }^{*}$, I. Baba ${ }^{1}$, Dafit Ferianto ${ }^{1}$, Supaat Zakaria ${ }^{1}$, \\ Fakrurrazi Rahman ${ }^{1}$ \\ ${ }^{1}$ Faculty of Engineering Technology, Universiti Tun Hussein Onn Malaysia (UTHM), Parit Raja, \\ 86400 Batu Pahat, Johor, Malaysia
}

\begin{abstract}
Industrial sector becomes the main concern for developing country. By the time, it was increased rapidly. However, there are many problems observed such as maintenance scheduling, stock inventory and supply chain. Therefore, this research develops new inventory system to develop sustainable plant operation with a high capability to plant operation especially to stock inventory of machine component. In also required green application with minimised used on paper. This system is developed using Radio Frequency Identification (RFID) for inventory control which integrated with web-based system. This system consists of several modules such as station module, item module and item request module and report of critical stock in the store. This system can be controlled from a hand-phone with internet connection or automatic alert such as Short Massage Send (SMS) and email. The developed system is very effective in monitoring the stock material through the barcode, supply chain and worker performance as well as to reduce the lead time for maintenance activities of the company through sustainable plant operation.
\end{abstract}

\section{Introduction}

It is widely acknowledged in literature that the design of Inventory Management Systems is of significant importance for the overall performance of manufacturing companies. Although different definitions exist, Inventory Management Systems are generally described as integrated systems designed to integrate, standardise and automate decision processes related to the management and control of inventories [1]. Inventory Management Systems in other words, provide the information to decision-makers within organisations at a strategic, tactical and operational level in order to support inventory decisions [2-3].

\footnotetext{
* Corresponding author: mutalib@uthm.edu.my
} 


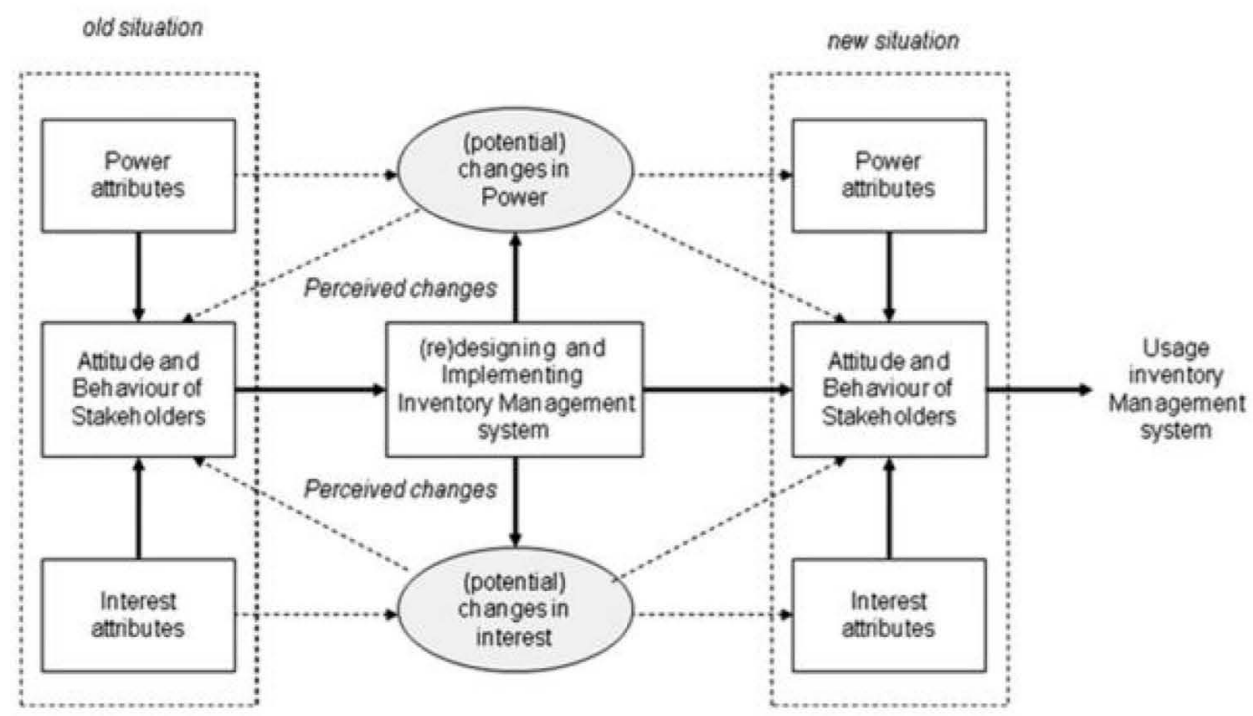

Fig. 1. Conceptual model of the implementation and usage of inventory systems network [1].

With the concern and support to The Internet of Things (IOT) industry constantly strengthening, the IOT has made full use of next generation IT technologies among the industries and has been widely applied in smart transportation, logistics management, environmental protection, public safety, smart household and other fields. In the aspect of logistics management, it can greatly reduce labour force, improve the efficiency of the operation speed and storage, and also decrease logistics costs. Meanwhile, it combined with a supply chain management system effectively and suppliers, manufacturers, customers are strongly united by Information technology, which can reduce inventory risk effectively [4].

The industrial production index has been increased for last few years. However, it is inline with the problems observed. Nowadays, there are many companies which not completed by inventory system that can affect to the bad maintenance schedule, high cost and low profit of company [5]. The development of inventory system integrated with webbased is quite needed to solve the problem by improving communication in related staff. The inventory system basically developed using RFID system where the main components of RFIDare shownn in Fig. 2.

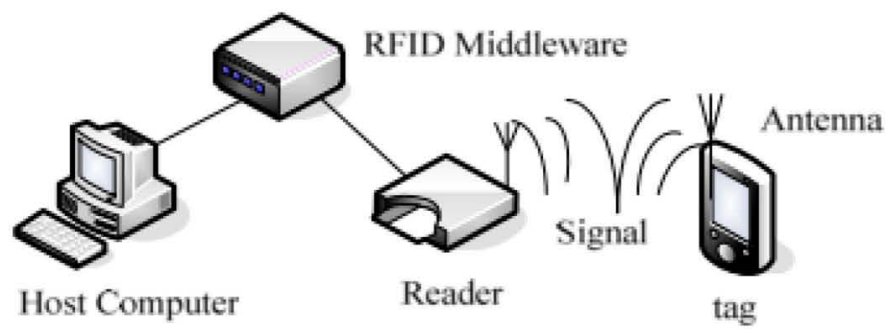

Fig. 2. The main components of an RFID system [4].

The several influences of the inventory system may caused by an unsuitable inventory system such as quantity of the components or stock is not updated automatically, delay for receiving components and unaware of the store keeper in component supply [6-7]. Therefore, this study aims to develop a new inventory system which integrated with report 
management for improving maintenance scheduling. This research is believed will sustain the plant production and improve the income of the company.

\subsection{Maintenance types.}

There are three types of maintenance in use in the company such as [8]:

i. Preventive maintenance, where equipment is maintained before breakdown occurs. This type of maintenance has many different variations and is subject of various researches to determine best and most efficient way to maintain equipment. Recent studies have shown that Preventive maintenance is effective in preventing age related failures of the equipment. For random failure patterns which amount to $80 \%$ of the failure patterns, condition monitoring proves to be effective.

ii. Operational maintenance, where equipment is maintained by using.

iii. Corrective maintenance, where equipment is maintained after break down. This maintenance is often more expensive because the worn equipment can damage other parts and cause multiple damage.

\subsection{Integrated optimal reliable design, production, and maintenance planning.}

In multipurpose process plants, which are characterised by sharing different resources (equipment, manpower etc.) for production, unplanned equipment shutdown could affect the timely production of products and hence process profitability. Many approaches have been proposed to ensure high equipment availability by combining design, production, and scheduling frameworks with a maintenance optimisation framework. In these approaches, the initial reliability characteristics of equipment, which also determine equipment availability, are considered fixed by problem definition. In this work, a combined design, production and maintenance planning formulation for multipurpose process plants is extended to incorporate the reliability allocation problem at the design stage and the equipment initial reliabilities are made and can be improved by increasing the reliability of equipment and/or adding redundancy like shown in Fig. 3 [9].

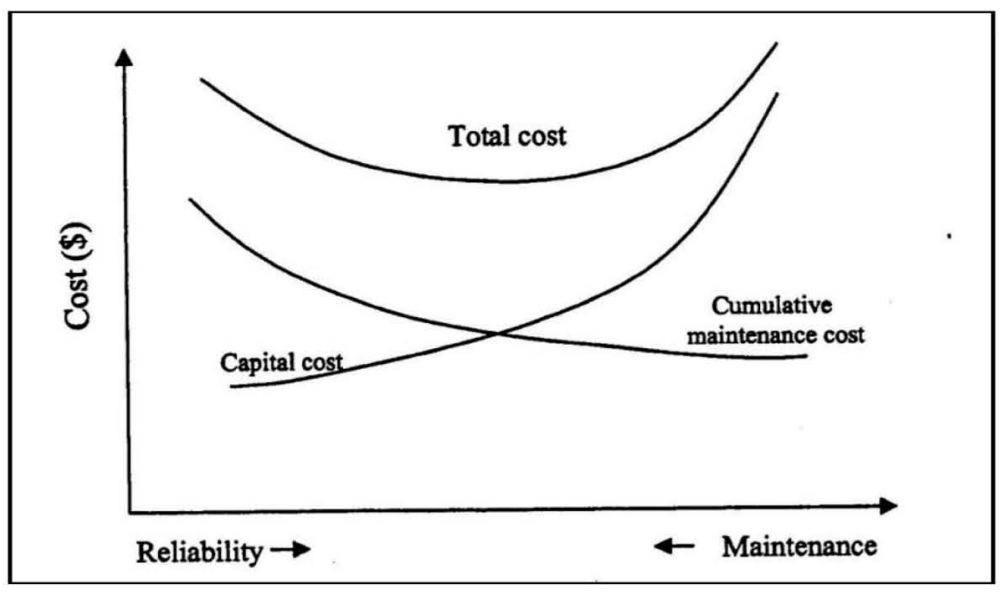

Fig. 3. Reliability versus maintenance costs to achieve a high availability [9]. 


\subsection{Inventory theory}

The goal of inventory usually comprises elements such as re-order level and re-order quantities which minimise total inventory cost (Fig.4), subject to a given service level. Total inventory cost normally ordering, setup cost, unit purchase costs, holding costs and shortage costs.

The Economic Order Quantity (EOQ), where inventory costs are minimised for independent demand. According to Sanjoy et al., (2015) [10] study on the classic economic lot size model, which recommends an optimal production batch by a trade-off of the inventory holding costs against production change-over costs.

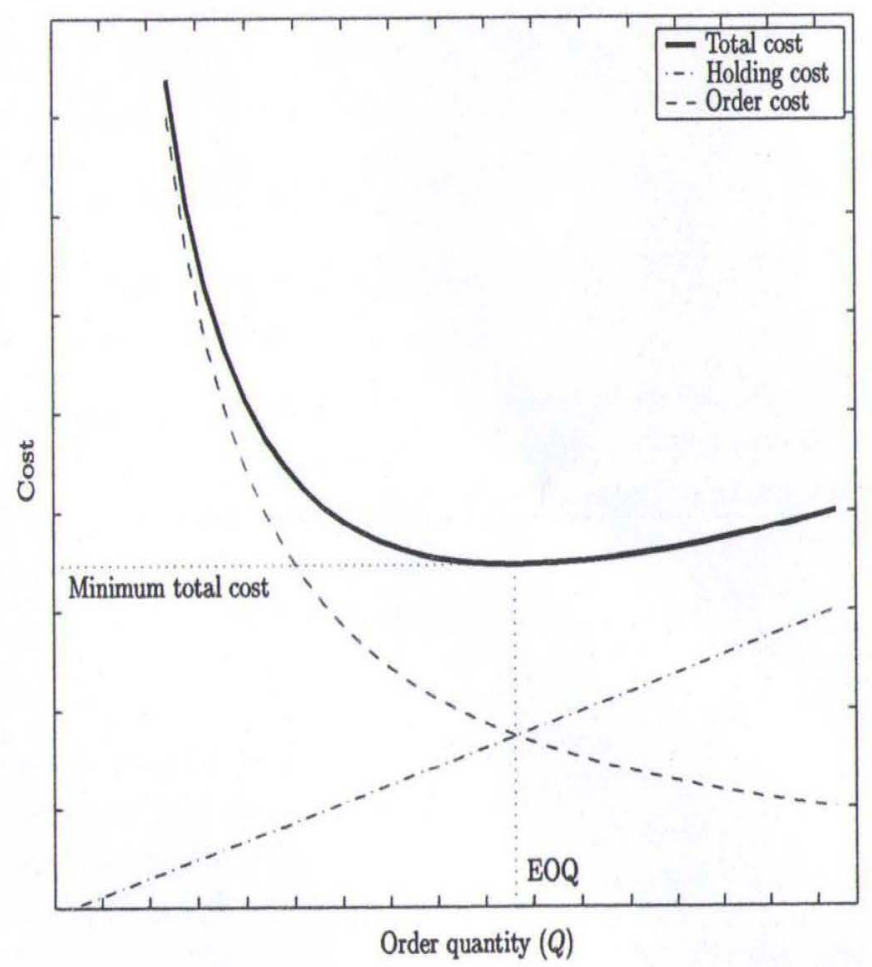

Fig. 4. A graphical depiction of the concept of an economic order quantity with alocation cost [10, 11].

\subsection{Stock control and inventory}

Stock control is used to show how much stock you have at a point in time, and how you keep track of it. It applies to every item you use to produce from raw materials to finished goods and whether it is a product or service. It covers stock at each stage of the production process, from purchase and delivery to using and re-ordering the stock [11]. 


\subsection{Using RFID for inventory control, stock security and quality management.}

Radio Frequency Identification (RFID) allows a business to identify individual products and components, and to track them throughout the supply chain from production to pointof-sale. An RFID tag is a tiny microchip, plus a small aerial, which can contain a range of digital information about the particular item. Tags are encapsulated in plastic, paper or similar material, and fixed to the product or its packaging, to a pallet or container, or even to a van or delivery truck. The tag is integrated by an RFID reader, which transmits and receives radio signals to and from the tag. Readers can range in size from a hand-held device to a 'portal' through which several tagged devices can be passed at once, eg on a pallet. Readers can be placed at different positions within a factory or warehouse to show when goods are moved, providing continuous inventory control. The benefits of this system are more efficient stock control and improved security make it particularly attractive to retailers, wholesalers or distributors [5].

\section{Methodology}

This research is conducted at Sungai Ambat Palm Oil Millstore department and involves of selected major key machinery which will give a significant effect to the maintenance and operation of the mill. The system inventory is developed to assist Sungai Ambat Management to improve maintenance scheduling to avoid major breakdowns which lead to profit lost to the company via reducing of inventory cost, time to locate and count materials.

\subsection{Pre-trial / Dry -run}

The coding system has given an impact the whole inventory system. The dry - run test, including coding the part, testing the scanner and system and software like shown in Fig. 5. 


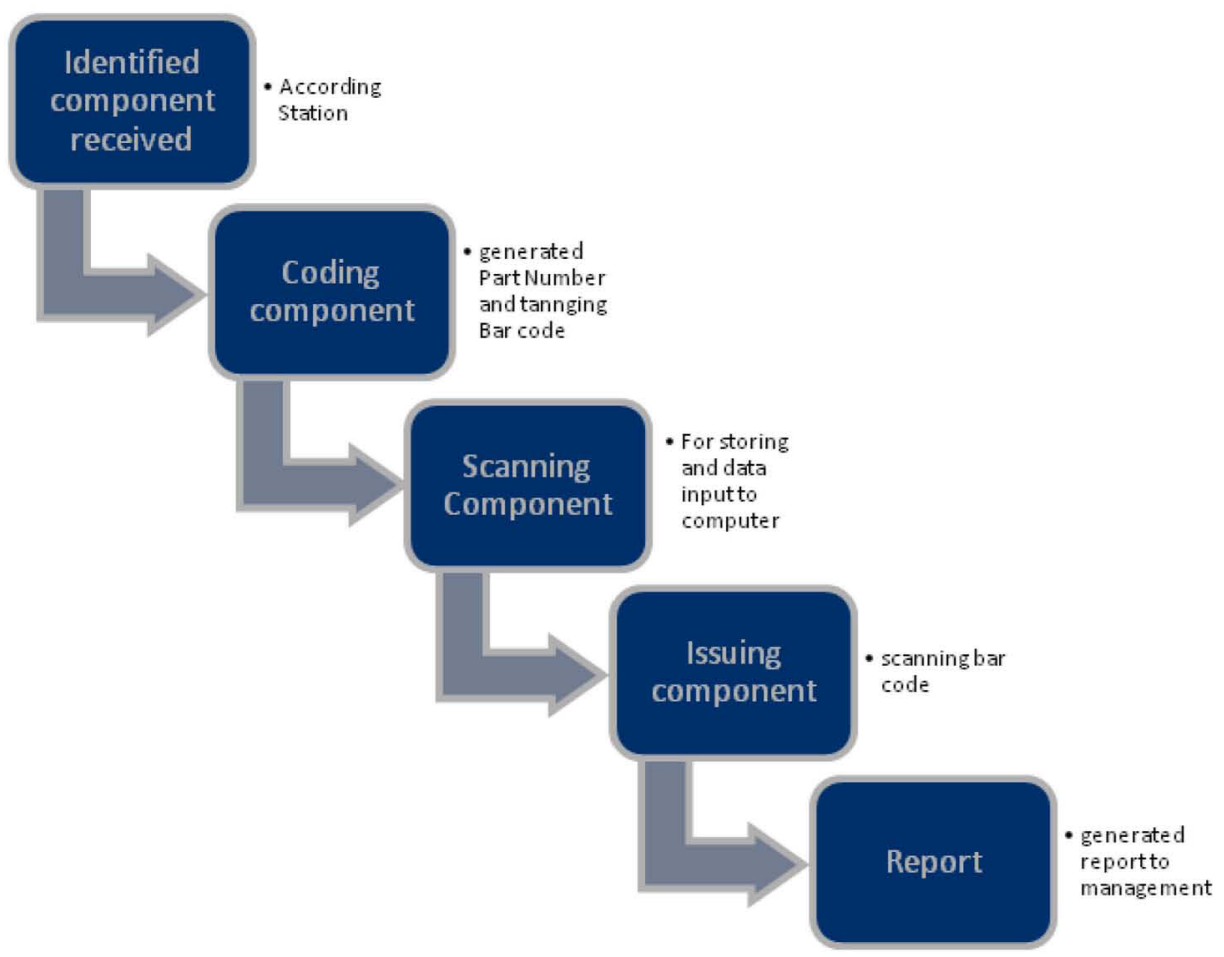

Fig. 5. Flow of pre-trial/dry-run process.

\subsection{Testing}

Testing will carry out on barcode itself. The simulation will carry out for few selected items to determine the equipment which reads the barcode function according with system like shown in Fig. 6.

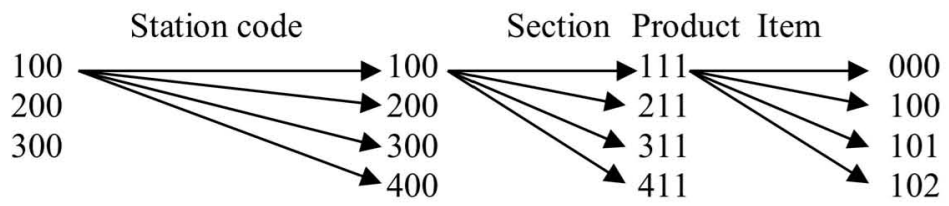

Fig. 6. Tagging system - bar coding system.

\subsection{Synchronization}

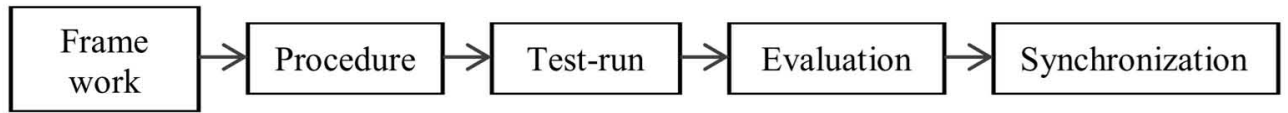

Fig. 7. Synchronization process of the inventory system. 


\subsection{Oil Palm Plant Inventory System (OPIS)}

This Oil Palm Plant Inventory System, called OPIS. This software provides business solutions for managing simple purchase order and stock inventory in the plant. Inventory management is the management of that list of material in stock. Inventory is a list of goods in stock i.e. total amount of materials contained in a unit or store. Buffer stock should be kept in order to meet the uncertainties in the market, i.e. in the demand of goods as well as to meet the time lag from supplier to user. Inventory can be of different types like raw material inventory, work in progress inventory, finished goods inventory and goods for resale inventory. Different components of an inventory management system are barcode scanner, barcode printer, barcode label, inventory software, etc. Inventory management software works along with barcode for inventory tracking and control.

\subsection{Web-based inventory system}

Internet-enabled electronic links between supply chain partners have allowed better coordination and collaboration among the various supply chain segments. Meanwhile, at the front of the supply chain, increasingly sophisticated point-of-sale systems can capture product demand patterns. More accurate sales-forecasting tools take some of the guesswork out of production and reduce the need for large inventory safety stocks. Tracking and tracing tools are also available to follow orders across borders and through the hands of different supply partners. The mechanism of tracking system is shown in Fig. 8.

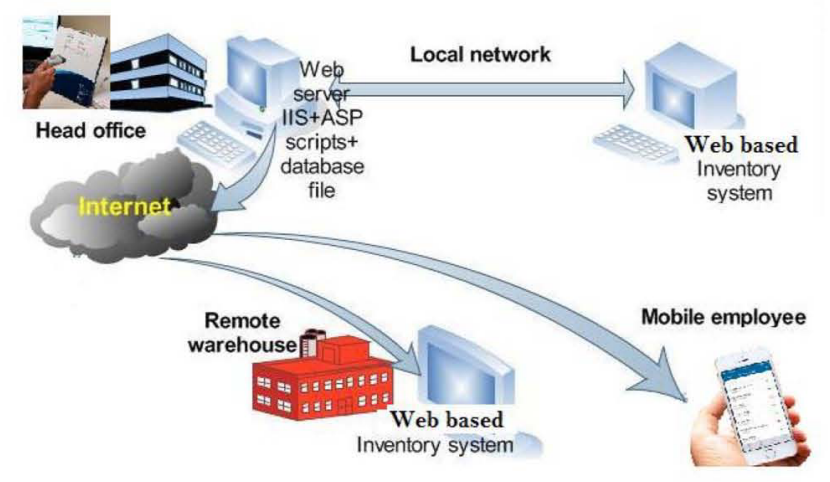

Fig. 8. Mechanism of the inventory system.

\subsection{New inventory system}

This system is easy to operate from anywhere and anytime control system because it controlled using the internet, alert system, SMS and Email.

\subsection{Database connection}

Name of the database that is designed as shown in Fig. 9, for SPMP is inventory.

15 Dim sql As New SqlConnection("Data Source=EIGHT \FARESSA; Initial Catalog=inventori; Integrated s

Fig. 9. Code to Connect to Database. 


\subsection{Log in}

OPIS enables two types of user login which are Kerani and Admin as shown in the Fig. 10.

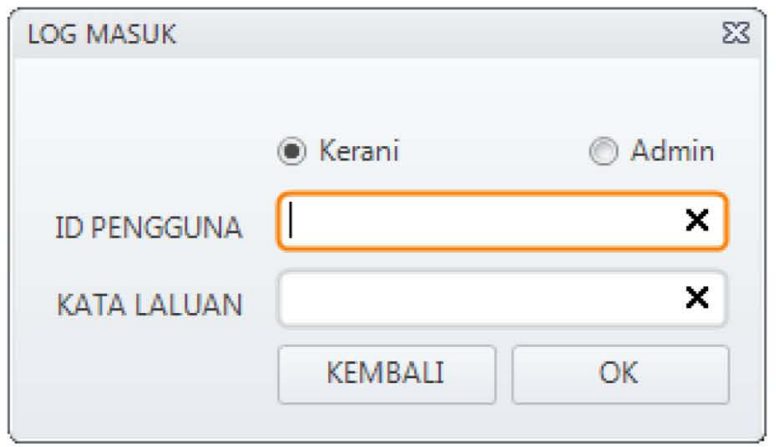

Fig. 10. Log In Interface.

\subsection{Item module}

Item module as shown in Fig. 11 is used by secretary to register new item and generating barcode for each item.

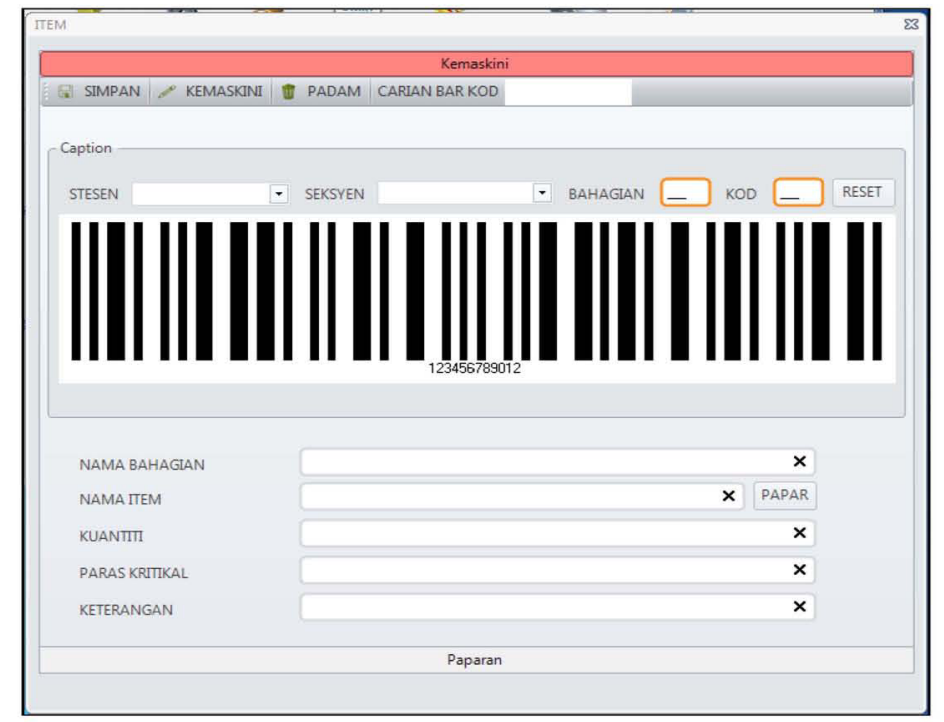

Fig. 11. Item Form Interface.

\subsection{Item request module}

The item request module will be accessed by secretary to manage stock in and stock out of an item. The request form must be signed by a supervisor before proceeding with this module. Staff id is required to identify each transaction occurred. This form will calculate the stock left after being requested as shown in Fig. 12. 


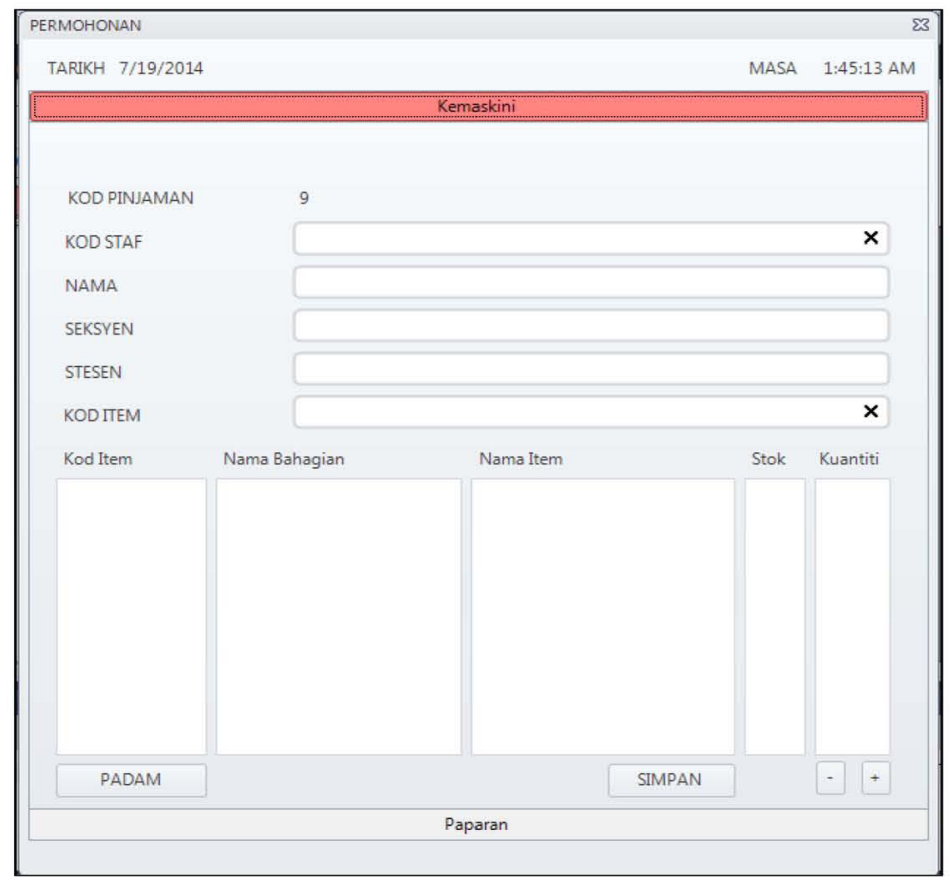

Fig. 12. Item Request Interface.

\subsection{Critical stock report}

OPIS also can generate critical stock reports if the current stock below the critical level as shown in Table 1.

Table 1. Critical Stock Report.

\begin{tabular}{|c|c|c|c|c|c|c|c|c|c|}
\hline \multicolumn{10}{|c|}{$\begin{array}{l}\text { LAPORAN HARIAN STOK YANG MENCAPAI PARAS KRITIKAL } \\
\text { 30-Jul-2014 }\end{array}$} \\
\hline Kod Bar & Keterangan & \begin{tabular}{|l|} 
Kod \\
Bahagian
\end{tabular} & \begin{tabular}{|l|} 
Nama \\
Bahagian
\end{tabular} & $\begin{array}{l}\text { Kod } \\
\text { Item }\end{array}$ & \begin{tabular}{|l} 
Nama \\
Item
\end{tabular} & \begin{tabular}{|l} 
Kod \\
Stesen
\end{tabular} & \begin{tabular}{|l|} 
Kod \\
Seksyen
\end{tabular} & \begin{tabular}{|l|} 
Paras \\
Kritikal
\end{tabular} & \begin{tabular}{|l} 
Stok \\
Semasa
\end{tabular} \\
\hline & & 0 & & 10 & & 0 & 0 & 0 & 0 \\
\hline 101100111333 & $\begin{array}{l}\text { WARNA } \\
\text { HIJAU, } \\
\text { DIBUAT } \\
\text { DARI KAYU } \\
\text { JATI }\end{array}$ & 111 & MEJA & 333 & $\begin{array}{l}\text { ALAS } \\
\text { MEJA }\end{array}$ & 101 & 100 & 6 & 0 \\
\hline 101100123441 & GG & 123 & \begin{tabular}{|l} 
JAM \\
TANGAN \\
ROLEX
\end{tabular} & 441 & AW & 101 & 100 & 7 & 3 \\
\hline 200102123445 & EVEREADY & 123 & \begin{tabular}{|l} 
JAM \\
TANGAN
\end{tabular} & 100 & BATERI & 200 & 102 & 50 & 3 \\
\hline 101100111 & $\mathrm{H}$ & 111 & MEJA & 119 & & 101 & 100 & 5 & 5 \\
\hline 101100111332 & EVEREADY & 123 & $\begin{array}{l}\text { JAM } \\
\text { TANGAN } \\
\text { ROLEX }\end{array}$ & 123 & BATERI & 101 & 100 & 50 & 49 \\
\hline
\end{tabular}




\subsection{Notification}

There are three types of notification for the critical stock value which are alert, SMS and Email. OPIS will display alert to the user each time user logs onto the system as shown in Fig. 13. OPIS also will send SMS to administrator to inform user about the critical value stock. Partial code to send SMS and email.

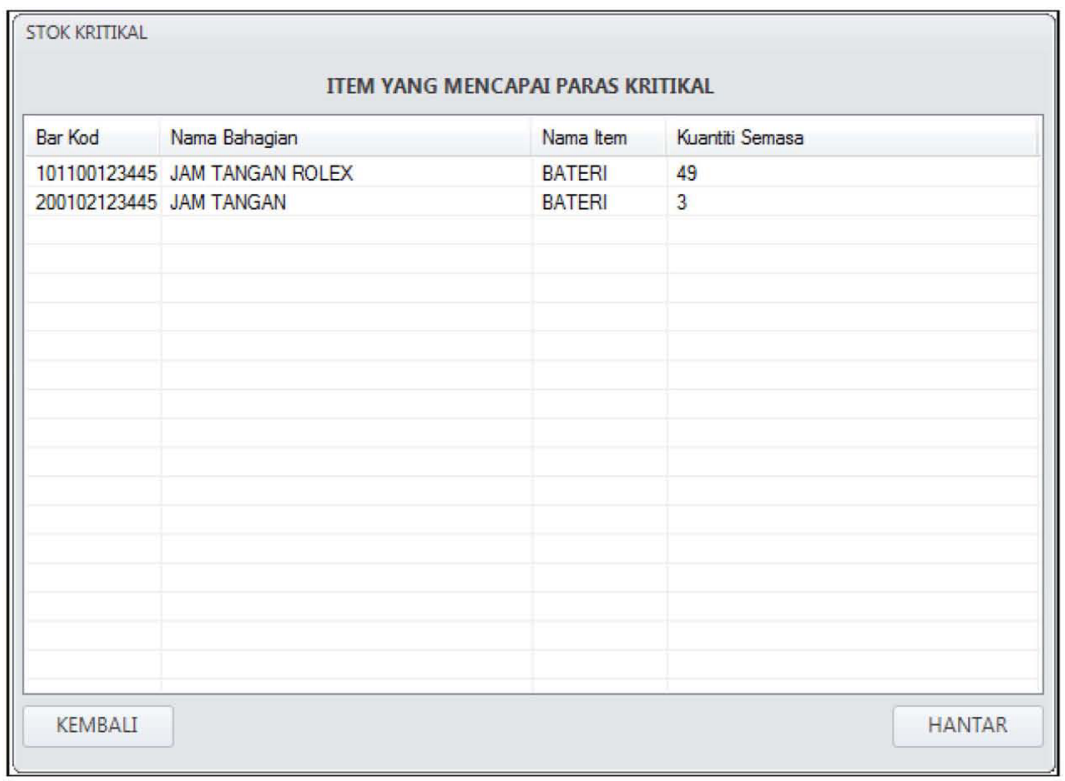

Fig. 13. Alert of Critical Stock.

\section{Conclusion}

New developing inventory system has been successfully developed by RFID system. It gives significant effect to the supply chain, stock monitoring, maintenance scheduling, and worker performance. In conclusion, inventory control system will be improved store system at Kilang Sawit RISDA Sg. Ambat (KSSA). Besides, by implementing this system, the work load of staff will be reduced and their job become easy and more productive.

The authors would like to thank to Universiti Tun Hussein Onn Malaysia (UTHM) and Centre for Graduate Studies - UTHM as well as Kilang Sawit RISDA Sg. Ambat (KSSA).

\section{References}

1. J. Vries, Int. J. Prod. Econ., 143, 233 (2013)

2. N.N. Nagarur, Hu, Tai san, Baid, K. Nirmal, Ind. Manage. Data Syst., 94 (9), 22 (1994)

3. Chen, H.M. Chen, Chang, C. Sian, International Journal of Business Information Systems, 4(1), 105 (2009)

4. X. Jing, P. Tang, Research and Design of The Intelligent Inventory Management System Based on RFID (Sixth International Symposium on Computational Intelligence and Design, 2013) 
5. K.H. Donselaar, R.A.C.M.B. Eindhoven, Int. J. Prod. Econ., 143, 440 (2013)

6. D.P. Warsing Jr., W. Wangwatcharakul, R.E. King, Comput. Oper. Res., 40, 2786 (2013)

7. S. Axsater, S. Viswanathan, Eur. J. Oper. Res., 221, 340 (2012)

8. X. Liu, W. Wang, R. Peng, Reliab. Eng. Syst. Safe, 137, 76 (2015)

9. D. Fu gui, L. Hui mei, L Bing de, Systems Engineering Procedia, 4, 298 (2012)

10. S.K. Paul, R. Sarker, D. Essam, Comput. Ind. Eng., 84, 101 (2015)

11. Z. Wang, F.T.S. Chan, Systems, 45(2), 326 (2015) 